\title{
Dermatology Online Journal
}

Volume 15 Number 2

February 2009

$\underline{\mathrm{DOJ}}$

\section{Contents}

\section{Sweet syndrome as the presenting symptom of hairy cell} leukemia

Filipa Ventura MD ${ }^{1}$, Joana Rocha MD ${ }^{1}$, Teresa Pereira MD $^{1}$, Herlander Marques $\mathrm{MD}^{2}$, Fernando Pardal MD ${ }^{3}$, Celeste Brito MD $^{1}$

Dermatology Online Journal 15 (2): 12

1. Dermatology and Venereology Department

2. Oncology Department

3. Pathology Department

Hospital de São Marcos, Braga, Portugal. filipamanuelventura@hotmail.com

Approximately 20 percent of patients with Sweet syndrome have an associated cancer [1]. Hematologic malignancies, most commonly acute myelogenous leukemia, account for 85 percent of the associated malignancies $[\underline{1}, \underline{2}, \underline{3}]$. The most common solid tumors are those of the genitourinary tract [4]. We report the case of a patient with Sweet syndrome as the presenting symptom of hairy cell leukemia.

\section{Case Report}

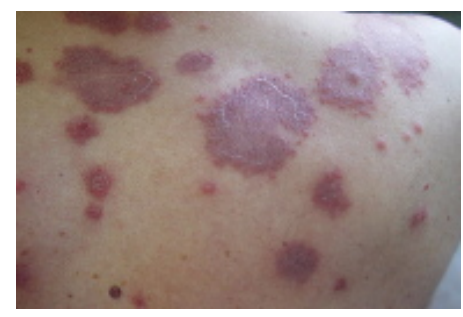

Figure 1

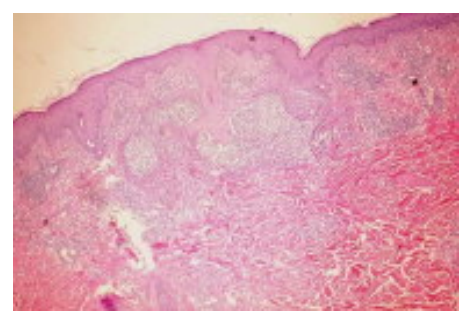

Figure 2

Figure 1. Violaceous papules and plaques on the back Figure 2. The skin biopsy showed a diffuse ne utrophilic infiltrate within the upper dermis with involvement of several follicular units (H\&E, x100)

A 62-year-old caucasian man, otherwise healthy, presented with a 3 -week history of a progressive skin eruption asymetrically distributed on the upper extremities and trunk. Dermatologic findings were accompanied by fever $\left(39^{\circ} \mathrm{C}\right)$, asthenia, anorexia, and weight loss. He was not taking any medication. There was no family history of skin disorders. Physical examination revealed asymptomatic, violaceous,

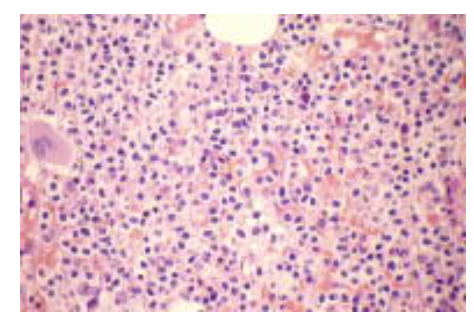

Figure 3

Figure 3. Bone marrow 
round, or irregularly shaped papules and plaques, covered with a fine scale. The lesions varied in diameter from 0.5 to $4 \mathrm{~cm}$ (Fig. 1). The patient had no adenopathy; there was no mucous or ocular involvement. Skin biopsy was taken and sent for histopathology and cultures.

Histopathology showed a diffuse neutrophilic infiltrate within the upper dermis with involvement of several follicular units, prominent leukocytoclasis, and absence of necrotizing vasculitis. Culture for bacteria, mycobacteria, and fungi were negative. The diagnosis of Sweet syndrome was made. Laboratory investigations revealed a macrocytic anemia $(10.2 \mathrm{~g} / \mathrm{dL})$, leukopenia $\left(2.5 \times 10^{9} / \mathrm{L}\right.$, with neutropenia and lymphopenia), and thrombocytopenia ( $\left.96 \times 10^{9} / \mathrm{L}\right)$. Some of the lymphocytes were atypical. Therefore, a bone marrow biopsy (Fig. 2) and the immunophenotype of bone marrow aspirate were performed. They were compatible with the diagnosis of hairy cell leukemia. Chest and abdominal CT scan showed axillary and mediastinal lymphadenopathies and a pulmonary involvement characterized by several micronodules. Systemic prednisolone $60 \mathrm{mg}$ daily had been initiated however patient's condition deteriorated and he died one month later due to a sepsis.

\section{Dis cussion}

The pathogenesis of Sweet syndrome remains to be definitively determined. Indeed, it may be multifactorial and many etiologies, not necessarily exclusive, have been postulated. A hipersensitivity reaction to an eliciting bacterial, viral, or tumor antigen may promote the development of Sweet syndrome is one of the hypothesis $[\underline{5}, \underline{6}]$.

Hairy cell leukemia (HCL) is an uncommon, chronic B cell lymphoproliferative disorder characterized by pancytopenia, splenomegaly, and the presence of atypical lymphocytes in the bone marrow and peripheral blood. Termed "leukemic reticuloendotheliosis" in 1958 and renamed hairy cell leukemia in the 1960s to describe the cytoplasmic projections observed on the surface of the malignant cells. HCL is usually an indolent disorder whose course is dominated by pancytopenia and recurrent infections. This disease affects predominantly middle-aged men [7]. As for other types of leukemia, the cause of HCL is not known. Patients can be asymptomatic at presentation or present with a variety of clinical signs that include anemia, bleeding, and life-threatening sepsis []. Approximately onequarter of patients present with fatigue, weakness, and weight loss []], just like our patient.

The association between Sweet syndrome and malignancies is very significant. Recommendations for the initial malignancy workup in newly diagnosed Sweet syndrome patients without a prior cancer were proposed by Cohen and Kurzrock in 1993 [1] . Malignancy-associated Sweet syndrome is most commonly related to acute myelogenous leukemia. Our patient presented Sweet syndrome associated with hairy cell leukemia, which has rarely been reported. This is the eighth case of this association reported in literature []].

\section{References}

1. Cohen PR, Kurzrock R. Sweet syndrome and cancer. Clin Dermatol. 1993;11:149-157. [PubMed] 
2. Cohen PR et al. Malignancy-associated Sweet's syndrome: Review of the world literature. J Clin Oncol. 1988;6:1887-1897. [PubMed]

3. Haverstock C, Libecco JF, Sadeghi P, Maytin E. Tender erythematous plaques in a woman with acute myelogenous leukemia. Arch Dermatol. 2006;142:235-240. [ubMed]

4. Hussein K, Nanda A, Al-Sabah H, Alsaleh QA. Sweet's syndrome (acute febrile neutrophilic dermatosis) associated with adenocarcinoma of prostate and transitional cell carcinoma of urinary bladder. J Eur Acad Dermatol Venereol. 2005;19:597-599. [ubMed]

5. Cohen PR. Sweet's syndrome - a comprehensive review of an acute febrile neutrophilic dermatosis. Orphanet Journal of Rare Diseases. 2007;2:34-62. [ubMed]

6. Honigsmann $\mathrm{H}$, Cohen PR, Wolff. Acute febrile neutrophilic dermatosis (Sweet's syndrome). (Chapter 94). In Fitzpatrick's Dermatology in General Medicine 6th edition. Edited by: Freedberg IM, Eisen AZ, Wolff K, Austen KF, Goldsmith LA, Katz SI, Fitzpatrick TB. New York: McGraw-Hill Health Professions Division;2003:949955.

7. Tallman MS, Hakimain D, Peterson LC. Hairy cell Leukemia. In Clinical Oncology 2th edition. Camden NJ. Churchill Livingstone;1999:2564-2578.

8. Levy RM, Junkins-Hopkins JM, Turchi JJ, James WD. Sweet syndrome as the presenting symptom of relapsed hairy cell leukemia. Arch Dermatol. 2002;138:1551-1554. [ubMed]

(C) 2009 Dermatology Online Journal 